\title{
Enhanced selective metal adsorption on optimised agroforestry waste mixtures
}

\author{
Emilio Rosales ${ }^{\mathrm{a}, \mathrm{b}, *}$, Laura Ferreira ${ }^{\mathrm{a}}$, M. Ángeles Sanromán ${ }^{\mathrm{a}}$, Teresa Tavares ${ }^{\mathrm{b}}$, Marta Pazos ${ }^{\mathrm{a}}$ \\ a Department of Chemical Engineering, University of Vigo, Isaac Newton Building, Campus As Lagoas Marcosende, 36310 Vigo, Spain \\ ${ }^{\mathrm{b}}$ Centro de Engenharia Biológica, Universidade do Minho, Campus de Gualtar, 4710-057 Braga, Portugal
}

\section{H I G H L I G H T S}

- Agroforestry wastes present good sorption capacities for a mixture of several metals.

- A mixture of biosorbents increases the total removal of metals.

- Optimisation of the biosorbent mixture proportions maximises metal removal.

- Recovery of metals can be achieved by treatment with weak acids.

\section{A R T I C L E I N F O}

\section{Article history:}

Received 7 November 2014

Received in revised form 19 January 2015

Accepted 23 January 2015

Available online 31 January 2015

\section{Keywords:}

Multi-metals

Agroforestry wastes

Biosorption

Simplex-centroid mixture design

\begin{abstract}
A B S T R A C T
The aim of this work is to ascertain the potentials of different agroforestry wastes to be used as biosorbents in the removal of a mixture of heavy metals. Fern (FE), rice husk (RI) and oak leaves (OA) presented the best removal percentages for $\mathrm{Cu}(\mathrm{II})$ and $\mathrm{Ni}(\mathrm{II}), \mathrm{Mn}(\mathrm{II})$ and $\mathrm{Zn}(\mathrm{II})$ and $\mathrm{Cr}(\mathrm{VI})$, respectively. The performance of a mixture of these three biosorbents was evaluated, and an improvement of $10 \%$ in the overall removal was obtained $(19.25 \mathrm{mg} / \mathrm{g})$. The optimum mixture proportions were determined using simplexcentroid mixture design method ( $\mathrm{FE}: \mathrm{OA}: \mathrm{RI}=50: 13.7: 36.3$ ). The adsorption kinetics and isotherms of the optimised mixture were fit by the pseudo-first order kinetic model and Langmuir isotherm. The adsorption mechanism was studied, and the effects of the carboxylic, hydroxyl and phenolic groups on metal-biomass binding were demonstrated. Finally, the recoveries of the metals using biomass were investigated, and cationic metal recoveries of $100 \%$ were achieved when acidic solutions were used.
\end{abstract}

( 2015 Elsevier Ltd. All rights reserved.

\section{Introduction}

The processes of a wide variety of industries such as tanneries, plating, textile, mining, cosmetics, pharmaceutical and paper use many metals ions, including $\mathrm{Cr}(\mathrm{VI}), \mathrm{Cr}(\mathrm{III}), \mathrm{Mn}, \mathrm{Cu}, \mathrm{Zn}$ and $\mathrm{Ni}$ (Gupta et al., 2009). Once used, the compounds containing these metals can generate a wide range of wastewaters containing different pollutants. The amount of metal present in the wastewater is related to the operations developed in the industry. The removal of metals in effluent is required to attain the safe permissible metal limits and avoid the toxic and poisonous effects of these metals in

\footnotetext{
* Corresponding author at: Department of Chemical Engineering, University of Vigo, Isaac Newton Building, Campus As Lagoas Marcosende, 36310 Vigo, Spain. Tel.: +34 986812 304; fax: +34986812380.

E-mail addresses: emiliorv@uvigo.es (E. Rosales), ferreira@uvigo.es (L. Ferreira), sanroman@uvigo.es (M. Ángeles Sanromán), ttavares@deb.uminho.pt (T. Tavares), mcurras@uvigo.es (M. Pazos).
}

the environment. For example, $\mathrm{Cr}(\mathrm{VI})$ has been recognised as a carcinogenic and mutagenic agent (Brauer and Wetterhahn, 1991), and the presence of $\mathrm{Cr}(\mathrm{III})$ at concentrations exceeding $5.0 \mathrm{mg} / \mathrm{L}$ may be toxic for aquatic life (Pérez Marín et al., 2009).

A wide range of physical-chemical, biological and oxidative technologies have been proposed to treat wastewaters containing metals (Nguyen et al., 2013). Among the different treatments available, adsorption is one of the most attractive technologies because of its versatility, simple design, ease of operation and high efficiency for pollutant removal (Rosales et al., 2012). However, the main drawback of adsorption is the high cost of efficient adsorbent materials. Activated carbon is the most widely studied adsorbent and has been widely applied in industry, providing high removal rates; however, its cost is a drawback in its general use (Crini, 2006). Thus, alternative low cost and biodegradable adsorbents are required. A suitable low-cost adsorbent requires a porous structure, mechanical and chemical stability and affinity for the target pollutants (Cobas et al., 2014). Recent approaches suggest 


\section{Nomenclature}

$\begin{array}{ll}\text { CA } & \text { cane pruning wine grapes } \\ \text { OA } & \text { oak leaves } \\ \text { RI } & \text { rice husk } \\ \text { GR } & \text { grapefruit peelings } \\ \text { FE } & \text { fern } \\ \text { ME } & \text { mixture fern, oak leaves and rice husk } \\ \text { OAM } & \text { optimised biosorbent mixture } \\ q_{\mathrm{max}} & \text { model maximum achievable uptake by a system }(\mathrm{mg} / \mathrm{g}) \\ b_{\mathrm{L}} & \text { langmuir model affinity between the sorbate and sor- } \\ & \text { bent }(\mathrm{L} / \mathrm{mg}) \\ R^{2} & \text { linear correlation coefficient } \\ K_{\mathrm{F}} & \text { Freundlich model binding capacity }(\mathrm{mg} / \mathrm{g}) /(\mathrm{mg} / \mathrm{L})^{1 / n} \\ n_{\mathrm{F}} & \text { Freundlich model affinity between the sorbent and sor- } \\ & \text { bate } \\ K_{\mathrm{RP}} & \text { Redlich-Peterson model isotherm constant }(\mathrm{L} / \mathrm{g}) \\ a_{\mathrm{RP}} & \text { Redlich-Peterson model constant }(\mathrm{L} / \mathrm{mg})^{\beta_{\mathrm{RP}}} \\ \beta_{\mathrm{RP}} & \text { Redlich-Peterson model exponent }\end{array}$

\begin{tabular}{|c|c|}
\hline$K_{\mathrm{S}}$ & Sips model isotherm constant (L/g) \\
\hline$a_{\mathrm{s}}$ & Sips model constant (L/mg) \\
\hline$\beta_{\mathrm{S}}$ & Sips model exponent \\
\hline$k_{1}$ & Pseudo-first order rate constant ( $1 / \mathrm{min})$ \\
\hline$k_{2}$ & Pseudo-second rate constant $(\mathrm{g} /(\mathrm{mg} \min ))$ \\
\hline$C_{\mathrm{e}}$ & $\begin{array}{l}\text { concentration of metal solution at adsorption equilib- } \\
\text { rium }(\mathrm{mg} / \mathrm{L})\end{array}$ \\
\hline$C_{\mathrm{i}}$ & initial metal concentration of metal solution $(\mathrm{mg} / \mathrm{L})$ \\
\hline$q_{\mathrm{e}}$ & equilibrium adsorption capacity of biosorbent $(\mathrm{mg} / \mathrm{g})$ \\
\hline$q_{\mathrm{t}}$ & $\begin{array}{l}\text { amount of metal adsorbed per unit of biosorbent at time } \\
t(\mathrm{mg} / \mathrm{g})\end{array}$ \\
\hline$t$ & contact time (min) \\
\hline$R$ & universal gas constant $(\mathrm{J} /(\mathrm{mol} \mathrm{kg})$ \\
\hline$T$ & temperature $\left({ }^{\circ} \mathrm{C}\right)$ \\
\hline$k_{\text {id }}$ & intra-particle diffusion rate constant $\left(\mathrm{mg} /\left(\mathrm{g} \mathrm{h}^{0.5}\right)\right)$ \\
\hline
\end{tabular}

the utilisation of non-conventional adsorbents; natural clays (Iglesias et al., 2013; Padilla-Ortega et al., 2013), various industrial and agricultural materials such as hazelnut straws, peanut shell, banana peel, orange peel, walnut shell, rice husk and sawdust (Nguyen et al., 2013; Alothman et al., 2013; Ma et al., 2014; Park et al., 2008; Krishnani et al., 2008; Abdolali et al., 2014a) and forestry materials such as fern or oak leaves (Prasad and Freitas, 2000; Barriada et al., 2009) have been tested. These agroforestry materials have been mainly applied to the removal of a single or a couple of metals, while little attention has been paid to the simultaneous adsorption of multiple metals (Krishnani et al., 2008; Abdolali et al., 2014b; Hossain et al., 2014a).

The goal of this study is to ascertain the abilities of different agroforestry wastes as alternative low-cost biosorbents for the removal of wastewater streams containing different metals. First, the adsorption potentials of the agroforestry wastes were investigated. Then, the performance of the combination of the biosorbents were evaluated, and the composition of the mixed biosorbents was optimised using response surface methodology. Isotherms and kinetic data were also obtained. Finally, the adsorption mechanism was studied, and biosorbent recovery was evaluated.

\section{Experimental}

\subsection{Reagents}

A stock solution containing $\mathrm{Cr}, \mathrm{Cu}, \mathrm{Mn}, \mathrm{Ni}$ and $\mathrm{Zn}$ was obtained by dissolving the metal salts in water. $\mathrm{ZnCl}_{2}, \mathrm{CuCl}_{2} \cdot 2 \mathrm{H}_{2} \mathrm{O}, \mathrm{MnCl}_{2}$ $.4 \mathrm{H}_{2} \mathrm{O}$ and $\mathrm{NiCl}_{2} \cdot 6 \mathrm{H}_{2} \mathrm{O}$ were purchased from Merck, and potassium dichromate $\left(\mathrm{K}_{2} \mathrm{Cr}_{2} \mathrm{O}_{7}\right)$ was obtained from Sigma-Aldrich. All the used chemicals were reagent grade.

\subsection{Agroforestry wastes}

The materials used in the study were agriculture and forestry wastes. Cane pruning wine grapes (CA), fern (FE), eucalyptus bark $(E U)$, oak leaves (OA), grapefruit (GR) and rice husk (RI) were provided by local suppliers. The wastes were washed three times with distilled water, dried in an oven at $60^{\circ} \mathrm{C}$ for $24 \mathrm{~h}$ and then grounded to pass through a $1-\mathrm{mm}$ sieve before use.

\subsection{Metal adsorption by biosorbents}

Adsorption studies were performed individually for each biosorbent in Erlenmeyer flasks $(250 \mathrm{~mL})$ containing $1 \mathrm{~g}$ of biosorbent with a working volume of $150 \mathrm{~mL}$. The experiments were carried out at $25^{\circ} \mathrm{C}$ and $150 \mathrm{rpm}$ for $4 \mathrm{~h}$. A synthetic wastewater was prepared containing a mixture of the different metals. The initial concentration of each metal in this synthetic wastewater was $50 \mathrm{mg} / \mathrm{L}$, resulting in a total metal content of $250 \mathrm{mg} / \mathrm{L}$.

The metal adsorption assays using a mixture of untreated biosorbents were performed under the same conditions with a final mass of $1 \mathrm{~g}$. Kinetic and isotherm studies were carried out under the same conditions as previously described. For the isotherms assays, the concentration of each metal in the synthetic wastewater ranged from $6-400 \mathrm{mg} / \mathrm{L}$.

\subsection{Adsorption process mechanism}

The adsorption mechanism was evaluated by modifying the surfaces of the biosorbents using different selected chemical agents. Chemical modification methods could activate/deactivate the available binding sites on the biomass surface (Abdolali et al., 2014a). To evaluate the adsorption mechanism, the chemical blocking of functional groups was applied. The esterification of carboxylic acids with methanol- $\mathrm{HCl}$ (HM-ME) and the methylation of hydroxyl and phenolic groups with formaldehyde (FO-ME) were carried out. The carboxylic acids present in the biosorbents were esterified by alcohols in the presence of a suitable acidic catalyst $(\mathrm{HCl})$ according to Gardea-Torresdey (1990). The modification of the biosorbents with formaldehyde was performed according to Deshkar et al. (1990).

\subsection{Recovery of the metals}

After adsorption, the biosorbent was recovered by filtration and dried in a stove at $60^{\circ} \mathrm{C}$ for $24 \mathrm{~h}$. The biosorbent loaded with metals was then treated with an eluent (water, $\mathrm{HCl} 0.1 \mathrm{~N}$ and $\mathrm{HNO}_{3}$ $0.1 \mathrm{~N}$ ). Desorption tests were performed using $1 \mathrm{~g}$ of the used biosorbent in $150 \mathrm{~mL}$ of the eluent. After $120 \mathrm{~min}$ at $150 \mathrm{rpm}$, the samples were filtered, and the $\mathrm{pH}$ and metal concentrations in the liquid were determined. 


\subsection{Optimisation of biosorbent mixture}

To optimise the mixture, a tool-like experimental design was selected. This design allows a reduction in the number of experiments required to optimise the biosorbent composition and to fit a model equation to the obtained data.

The optimum composition of the biosorbent mixture was determined using simplex-centroid mixture design (SCMD). SCMD is a type of experimental design used to analyse the response of two or more components to obtain a final product with a different composition. The proportion $X_{\mathrm{i}}$ of a component in the mixture must satisfy the constraints $0 \leqslant X_{\mathrm{i}} \leqslant 1$, where $i=1,2, \ldots, q$, and $\sum X_{\mathrm{i}}=1$, where $q$ is the number of components. The geometric description of the spatial representation will depend on the number of components $q$ (a line for $q=2$, an equilateral triangle for $q=3$, etc.) (Yoshiara et al., 2012).

The regression model equations were fitted to a quadratic expression as follows:

$Y_{\mathrm{i}}=\sum b_{\mathrm{j}} X_{\mathrm{j}}+\sum b_{\mathrm{jk}} X_{\mathrm{j}} X_{\mathrm{k}}$

where $Y$ is the response, $b$ are the constants and $X$ are the indepent parameters. Statistical analysis of the model was performed to evaluate the analysis of variance (ANOVA) using Design Expert ${ }^{\circledR}$ 8.0.0 software (Stat-Ease Inc., Minneapolis, USA).

\subsection{Determination procedures}

\subsubsection{Metals determination}

The metal concentrations in the supernatant were determined using ICP-OES (PerkinElmer-Optima 8000). Hexavalent chromium was quantified by measuring the absorbance at $540 \mathrm{~nm}$ of the purple complex of $\mathrm{Cr}(\mathrm{VI})$ with 1,5-diphenylcarbazide in acidic solution. The $\mathrm{Cr}(\mathrm{III})$ concentration was calculated as the difference between the total chromium and the $\mathrm{Cr}(\mathrm{VI})$ concentration.

\subsubsection{Adsorption uptake and removal percentages}

The amount of metal adsorbed by the biosorbent (uptake) was calculated using the following expression:

$q_{\mathrm{t}}=\left(C_{\mathrm{i}}-C_{\mathrm{t}}\right) \cdot V / M$

where $C_{\mathrm{i}}$ and $C_{\mathrm{t}}(\mathrm{mg} / \mathrm{L})$ are the solute concentration at the beginning and through time $(t)$ in the solution, respectively, $q_{\mathrm{t}}$ is the solute uptake $(\mathrm{mg} / \mathrm{g}), V$ is the volume of the solution (L) and $M$ is the mass of the biosorbent $(\mathrm{g})$.

The removal percentage, (\%), was calculated using Eq. (3):

Metal removal $=100 \cdot\left(C_{\mathrm{i}}-C_{\mathrm{t}}\right) / C_{\mathrm{i}}$

where $C_{\mathrm{i}}$ and $C_{\mathrm{t}}(\mathrm{mg} / \mathrm{L})$ are the solute concentrations at the beginning and through time $(t)$ in the solution, respectively.

The obtained concentration and uptake profiles were fitted by a suitable kinetic or isotherm equation, and the rate constants or adsorption parameters were calculated using Sigma Plot 4.00 software. The Sigma Plot curve fitter uses an iterative procedure based on the Marquardt-Levenberg algorithm, which seeks the values of the parameters that minimise the sum of the squared differences between the observed and predicted values of the dependent variable.

\subsubsection{Characterisation of biosorbents}

The zero point charge (ZPC) was determined by mass titration (Noh and Schwarz, 2013). Approximately $50 \mathrm{~mL}$ of $0.1 \mathrm{M} \mathrm{NaNO}_{3}$ as the background electrolyte was transferred into a $250 \mathrm{~mL}$ of Erlenmeyer flask, and the solution $\mathrm{pH}$ was adjusted with diluted $\mathrm{HCl}$ and $\mathrm{NaOH}$ to the desired values ( 3 and 11). The final volume of the solution was $50 \mathrm{~mL}$. The mixture was shaken for $24 \mathrm{~h}$ and then filtered through filter paper. The $\mathrm{pH}$ in filtrate was measured with a CyberScanpH2100 Bench Meter (Eutech Instruments) after three-point calibration.

The acidic surface functional groups were quantified by Boehm titration (Boehm, 1966). First, a $0.3 \mathrm{~g}$ sample was mixed with $50 \mathrm{~mL}$ of $0.05 \mathrm{~mol} / \mathrm{L} \mathrm{NaOH}$ solution in a $250 \mathrm{~mL}$ Erlenmeyer flask. The flask was sealed and shaken for $24 \mathrm{~h}$ at room temperature. Then, the sample was separated by filtration, and the filtrate was titrated with $0.05 \mathrm{~mol} / \mathrm{L}$ of $\mathrm{HCl}$ standard solution. Finally, the amounts of the functional groups per gram of waste were calculated according to the hypothesis that carboxylic, lactonic and phenolic groups can react with $\mathrm{NaOH}$. The identification of basic groups (pirone and carbanion) was analogous to Boehm titration using $\mathrm{HCl}$ as acid.

Fourier-transform infrared (FT-IR) spectra of the biosorbents were recorded on an FT-IR spectrometer (model FT-IR/4100, Jasco). The samples were previously dried in an oven at $60{ }^{\circ} \mathrm{C}$ for $40 \mathrm{~min}$.

Scanning electron microscopy (SEM) was performed on a JEOL JSM-6700F equipped with an EDS (Oxford Inca Energy 300, Electron Microscopy Service, C.A.C.T.I., University of Vigo) using an accelerating voltage of $15 \mathrm{kV}$. The analysed biosorbents were coated with carbon for SEM observation.

\section{Results and discussion}

\subsection{Characterisation of biosorbents}

The chemical structure of the biosorbent is a key factor in the adsorption process; the selected biosorbents have been previously characterised using FTIR spectroscopy to determine the surface functional groups involved. The FTIR spectra are shown in the Supplementary data (S.1).

The selected agroforestry wastes present high carbohydrates/ lignin content, suggesting the presence of functional groups (methoxyl, phenolic, hydroxyl, aliphatic hydroxyl, carbonyl, etc.). Some of these groups suggest that the metal binding takes place by chelation, as reported by Komy et al. (2013). The most representative bands detected were identified, and similar functional groups were found on the adsorbents. The bands in the $3450-3200 \mathrm{~cm}^{-1}$ region could be indicative of the complex nature of the examined biomasses and assigned to hydroxyl and amine groups (Komy et al., 2013). The bands assigned to asymmetric and symmetric methyl and methylene stretching are located at 2950 and $2850 \mathrm{~cm}^{-1}$, carbonyl stretching corresponds to the band at $1800-1650 \mathrm{~cm}^{-1}$, the amide I and amide II bands are observed at 1652 and $1531 \mathrm{~cm}^{-1}$ (Li et al., 2010) and the band at $1050-1020 \mathrm{~cm}^{-1}$ is assigned to carbohydrate units (Barriada et al., 2009; Abdolali et al., 2014b; Komy et al., 2013). The hydroxyl and carboxyl functional groups are suitable for the adsorption and binding of heavy metals (Hossain et al., 2014b). These facts are in accordance with the reports of Barriada et al. (2009), Nguyen et al. (2013), who analysed agriculture and forestry wastes in the removal of metals. The FTIR spectra of the selected biosorbents verify that the biosorbents are mainly composed of lignocellulosic materials (lignin, cellulose and hemicellulose).

SEM pictures of some adsorbents (FE, OA, and RI) are shown in the Fig. S3a. Different structures were detected in FE and homogeneous structures for OA and RI. The EDS analyses are shown in Fig. S3b and the elemental composition detected consisted only in carbon and oxygen in the surface of the selected agroforestry waste (FE and $\mathrm{OA}$ ) but the RI presented a small amount of $\mathrm{P}, \mathrm{K}$ and $\mathrm{Mg}$

The surface characteristics of the wastes can be determined using the point of zero charge (PZC). The charge of the surface may be positive, negative or metal, and this charge determines the favoured adsorption. At $\mathrm{pH}>\mathrm{pH}_{\mathrm{PZC}}$ the adsorption of cations 
Table 1

Removal percentage of metals by each agroforestry waste biosorbent.

\begin{tabular}{lllrrll}
\hline & \multicolumn{7}{l}{ Metal removal (\%) } & \multicolumn{1}{l}{} \\
\cline { 2 - 7 } & $\mathrm{Cu}$ & $\mathrm{Ni}$ & $\mathrm{Mn}$ & $\mathrm{Cr}$ & $\mathrm{Zn}$ & $\mathrm{pH}$ \\
\hline FE & 94.50 & 40.48 & 11.84 & 64.60 & 41.54 & 4.52 \\
$\mathrm{OA}$ & 83.40 & 26.40 & 8.94 & 91.49 & 27.65 & 4.12 \\
$\mathrm{RI}$ & 68.77 & 21.77 & 50.50 & 6.33 & 89.74 & 4.83 \\
CA & 70.44 & 21.74 & 9.19 & 47.78 & 32.00 & 5.18 \\
GR & 49.76 & 14.62 & 6.61 & 0.26 & 24.89 & 4.97 \\
ME & 85.45 & 34.60 & 34.16 & 71.52 & 70.66 & 5.08 \\
\hline
\end{tabular}

is favoured, while at $\mathrm{pH}<\mathrm{pH}_{\mathrm{PZC}}$ is favoured the adsorption of anions (Li et al., 2010). The pH PZC values determined for FE, RI and $\mathrm{OA}$ were 5.33, 6.11 and 4.29, respectively. These results suggest that FE and OA have a strong cation adsorption ability. Meanwhile, FE and RI present higher capabilities for anion adsorption.

\subsection{Metal speciation}

The selected wastes were evaluated to remediate a synthetic wastewater containing a mixture of five metals: $\mathrm{Cu}(\mathrm{II}), \mathrm{Cr}(\mathrm{VI}) \mathrm{Ni}(\mathrm{II})$, $\mathrm{Zn}(\mathrm{II})$ and $\mathrm{Mn}(\mathrm{II})$. pH plays an important role in the adsorption process by affecting the surface charge of the biosorbent, the degree of ionisation and the speciation of the adsorbate (Yao et al., 2010). The experiments in this study were conducted at the natural $\mathrm{pH}$ of the multi-metal solution ( $\mathrm{pH} \sim 5$ ); Table 1 shows the variation in the experimental $\mathrm{pH}$ at the end of the experiments with different biosorbents. Acidification of the wastewater was observed in the experiments with $\mathrm{OA}(\mathrm{pH} 4.1)$ and $\mathrm{FE}(\mathrm{pH} 4.53)$. Based on these results, the metal speciation in the synthetic wastewater should be considered. Metal speciation greatly determines the behaviour and toxicity of metals in the environment. The metal speciation was obtained using the modelling software Visual MINTEQ (Fig. 1). At the initial metal concentrations and the natural solution $\mathrm{pH}, \mathrm{Ni}(\mathrm{II}), \mathrm{Zn}(\mathrm{II})$ and $\mathrm{Mn}(\mathrm{II})$ were present in their divalent cationic forms. Less than $1 \%$ of the present $\mathrm{Cu}$ existed as the monovalent cation $\left(\mathrm{CuOH}^{+}\right)$, while $\mathrm{Cr}$ was present in three different anionic forms $\left(\mathrm{HCrO}_{4}^{-}, \mathrm{Cr}_{2} \mathrm{O}_{7}^{2-}\right.$ and $\left.\mathrm{CrO}_{4}^{2-}\right)$, with the monovalent anion $\mathrm{HCrO}_{4}^{-}$ being prominent. Considering the final $\mathrm{pH}$ observed in the different experiments, no changes in the metal speciation are expected.

\subsection{Screening of biosorbents}

The adsorption of ions present in the synthetic multi-metal solution by agroforestry wastes was evaluated.

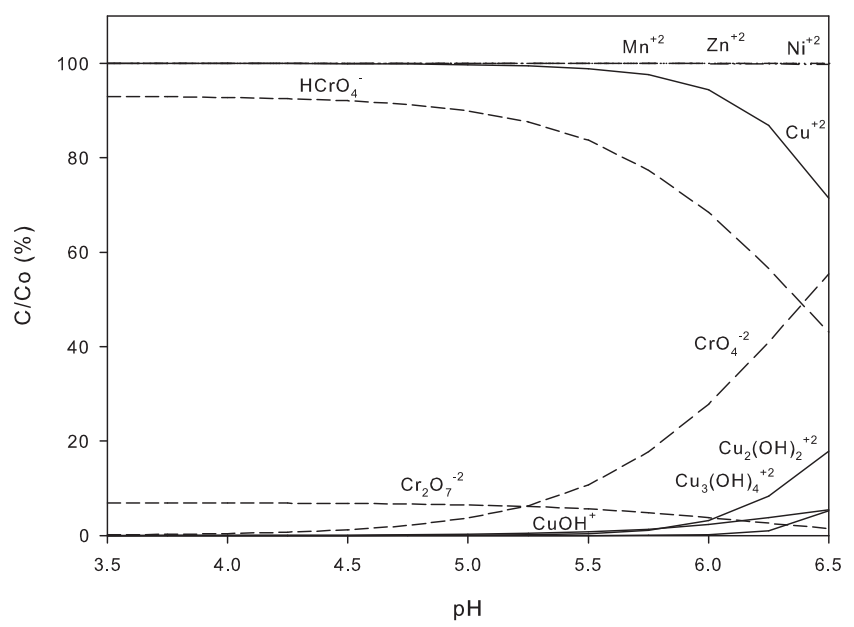

Fig. 1. Metal speciation of the mixture in the $\mathrm{pH}$ range of adsorption (data obtained based on software Visual MINTEQ).
The multi-metal mixture removal efficiencies of the five biosorbents are shown in Table 1. Among all metals, the maximum removals of $\mathrm{Cr}(\mathrm{VI}), \mathrm{Zn}(\mathrm{II})$ and $\mathrm{Cu}(\mathrm{II})$ were higher than those obtained for the other metals. The maximum removals achieved on the different biosorbents were nearly $90 \%$ for $\mathrm{Cr}(\mathrm{VI}), \mathrm{Zn}(\mathrm{II})$ and $\mathrm{Cu}(\mathrm{II})$. However, the obtained metal removal percentages for $\mathrm{Mn}(\mathrm{II})$ and $\mathrm{Ni}(\mathrm{II})$ were lower than 55\% for all of the tested biosorbents. The highest removals of copper and nickel were obtained by FE; RI performed the best for manganese and zinc removal, and OA was optimal for chromium removal. These results are in accordance with those reported by Fontes and Gomes (2003) and can be explained by the high affinity of cations for the carboxylic and hydroxyl groups of cellulose. This aspect is reinforced by the previously obtained IR spectra of the biosorbents, which indicate the presence of these carboxylic and hydroxyl groups. One special consideration pertains to chromium because it is present as an anion; (Krishnani et al., 2008) and other authors have suggested that carboxylic and hydroxyl groups present in pretreated rice husk probably act as electron donors in the reduction of chromium to $\mathrm{Cr}(\mathrm{III})$ and subsequent adsorption.

The acidic and basic contents of the adsorbents are directly connected with the metal binding properties. Therefore, it is necessary to estimate the different types of binding to discuss the adsorption mechanism. The obtained results show the amount of binding points in acidic sites (FE $1.813 \mathrm{mmol} / \mathrm{g}$, OA $2.917 \mathrm{mmol} / \mathrm{g}$, RI $0.458 \mathrm{mmol} / \mathrm{g}$, GR $1.167 \mathrm{mmol} / \mathrm{g}$, EU $1.917 \mathrm{mmol} / \mathrm{g}$ ) and basic sites (FE $3.208 \mathrm{mmol} /$ g, OA $3.000 \mathrm{mmol} / \mathrm{g}, \quad$ RI $3.167 \mathrm{mmol} / \mathrm{g}, \quad$ GR $2.917 \mathrm{mmol} / \mathrm{g}$, EU $3.000 \mathrm{mmol} / \mathrm{g}$ ). The amount of acidic sites present in the different wastes reflects the heterogeneity of the source materials.

The selected materials have been shown to effectively bind a number of heavy metal ions, but it is unlikely that all ions were bound equally. Hossain et al. (2014b) suggested that the binding capacity for individual ions is different from a unique metal adsorption system, although the adsorption depends on a number of factors such as ionic potential, ionic radius, chemical properties and hydrolysis. Fig. 2 shows the total adsorbed metals and the distribution of different ions related to the total content. The total amounts of metals adsorbed using FE, RI and OA ranged from 16.51 to $17.71 \mathrm{mg}_{\text {metals }} / \mathrm{g}_{\text {biosorbent }}$. Based on the obtained values, a competitive adsorption order could be determined. The sequences were different for each biosorbent evaluated. For FE and OA, the general binding affinity for the studied metals decreasing in the following order: $\mathrm{Cu}(\mathrm{II})>\mathrm{Cr}(\mathrm{VI})>\mathrm{Ni}(\mathrm{II})>\mathrm{Zn}(\mathrm{II})>\mathrm{Mn}(\mathrm{II})$. Meanwhile, the order for RI was $\mathrm{Zn}(\mathrm{II})>\mathrm{Cu}(\mathrm{II})>\mathrm{Mn}(\mathrm{II})>\mathrm{Ni}(\mathrm{II})>\mathrm{Cr}(\mathrm{VI})$, that for $\mathrm{CA}$ was $\mathrm{Cu}(\mathrm{II})>\mathrm{Cr}(\mathrm{VI})>\mathrm{Zn}(\mathrm{II})>\mathrm{Ni}(\mathrm{II})>\mathrm{Mn}(\mathrm{II})$, and that of $\mathrm{GP}$ was $\mathrm{Cu}(\mathrm{II})>\mathrm{Zn}(\mathrm{II})>\mathrm{Ni}(\mathrm{II})>\mathrm{Mn}(\mathrm{II})>\mathrm{Cr}(\mathrm{VI})$.

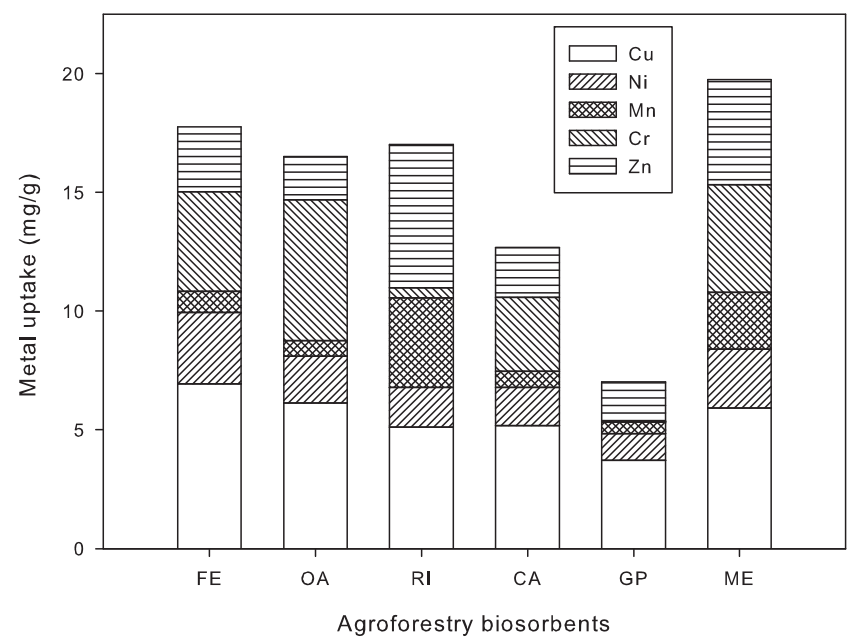

Fig. 2. Metal uptake (mg/g) obtained for the different natural wastes: $\mathrm{Cu}, \mathrm{Ni}, \mathrm{Mn}, \mathrm{Cr}$ and $\mathrm{Zn}$. 
Table 2

Analysis of functional groups in the mixture of biosorbents FE, OA, and RI in a ratio 1:1:1 for metal removal.

\begin{tabular}{|c|c|c|c|c|c|}
\hline \multicolumn{2}{|c|}{ Wavelength range $\left(\mathrm{cm}^{-1}\right)$} & \multicolumn{3}{|c|}{ Transmittance (\%) } & \multirow[t]{2}{*}{ Bond/functional group } \\
\hline Frequency & Difference & Unloaded & Loaded & Difference & \\
\hline $3500-3200$ & 2.8926 & 97.0729 & 99.2113 & 2.1384 & OH stretches from hydroxyl, phenolic and carboxylic groups* (various polysaccharides, alcohols) \\
\hline $3000-2850$ & 1.9285 & 92.4529 & 93.6298 & 1.1769 & $\mathrm{H}-\mathrm{C}-\mathrm{H}$ stretch*, $\mathrm{H}-\mathrm{C}-\mathrm{H}$ asymetric and simetris stretch/alkanes ${ }^{* *}$ (various aliphatic compounds) \\
\hline $1820-1680$ & 0.00 & 91.0512 & 91.9744 & 0.9232 & $\mathrm{C}=\mathrm{O}$, stretching vibration of carboxylate functional group* (pectin) \\
\hline $1550-1475$ & -0.9642 & 93.5546 & 93.5558 & 0.0012 & $\mathrm{C}-\mathrm{C}$ stretching in aromatic skeletons (lignin) $\mathrm{N}-\mathrm{O}$ asymetric stretch ${ }^{* *}$ \\
\hline $1475-1450$ & 0.00 & 90.9117 & 91.6175 & 0.7058 & $\mathrm{C}-\mathrm{H}$ band/alkanes ${ }^{* *}$ (lignin) \\
\hline $1450-1300$ & -1.9285 & 90.102 & 91.3539 & -1.2519 & Carbohydrate unit s (cellulose) \\
\hline $1300-1000$ & 5.00 & 69.061 & 74.0612 & 4.8212 & Carbohydrate units (cellulose/lignin/starch) \\
\hline
\end{tabular}

Ma et al., 2014.

** Abdolali et al., 2014a.

All the selected biosorbents presented a high affinity for the adsorption of $\mathrm{Cu}(\mathrm{II})$. $\mathrm{Cu}$ is known to form complexes with very high stabilities despite the poor basicity of the donor group (Krishnani et al., 2008).

\subsection{Biosorbent mixture adsorption and optimisation}

\subsubsection{Biosorbent mixture}

None of the selected biosorbents was able to remove all the metals in significant quantities. Therefore, the biosorbents that showed the best performances in metal removal were selected (FE-OA-RI), a mixture of these biosorbents was tested, and the results were compared with those obtained for the individual biosorbents. Initially, a 1:1:1 mixture of the three selected biosorbents was tested (ME). The attained results (Fig. 2) indicate an improvement in the total quantity of metals removed compared with the individual biosorbents because it is possible to remove a larger quantity of the combined metals using the mixture rather than using an individual biosorbent. The use of the mixture provides a selective environment for the adsorption of the different heavy metals (Barriada et al., 2009; Abdolali et al., 2014b). The improvement of total metal quantity removed using the mixture was more than $10 \%$ (19.25 mg/g of biosorbent), and the metals exhibited a more homogeneous affinity for ME in comparison with the individual biosorbents. Removal percentages higher than $70 \%$ were achieved for $\mathrm{Cu}(\mathrm{II}), \mathrm{Cr}(\mathrm{VI})$ and $\mathrm{Zn}(\mathrm{II})$, while removal percentages higher than $30 \%$ were obtained for $\mathrm{Ni}(\mathrm{II})$ and $\mathrm{Mn}$ (II) (Table 1 ).

FTIR analysis of the samples was carried out before and after the loading of the biosorbent mixture. The chemical shift and intensity of some bands changed due to heavy metal biosorption. The differences detected in the spectra are shown in Table 2. The band corresponding to the $\mathrm{C}-\mathrm{O}$ stretching of carboxylic acid, esters and ethers (1300-1000 $\mathrm{cm}^{-1}$ ) shifted to higher values. The changes in the peaks in the range of 3500-3200 and $1820-1680 \mathrm{~cm}^{-1}$ indicate the involvement of $\mathrm{OH}$ from hydroxyl, phenolic and carboxylic groups and the $\mathrm{C}=\mathrm{O}$ from carboxylate functional groups, respectively (Barriada et al., 2009; Abdolali et al., 2014b; Yao et al., 2010; Popescu et al., 2007).

\subsubsection{Biosorbent mixture optimisation}

The composition of the mixture of the three wastes was evaluated and optimised. An experimental design based on SCMD was selected.

A design of experiments was developed with a mixture of three components: FE, $X_{1}$; OA, $X_{2}$; and RI, $X_{3}$. The selected response was the metal removal percentage, $Y_{\mathrm{i}}$ (where $i=\mathrm{Cu}, \mathrm{Ni}, \mathrm{Mn}, \mathrm{Cr}, \mathrm{Zn}$ ). The response to a mixture depends on the proportions of the components present, and a restriction related to the biosorbent proportions $\left(\mathrm{X}_{1}+\mathrm{X}_{2}+\mathrm{X}_{3}=1\right)$ was incorporated to the model. 14 runs were required to develop a model and the response for each metal removal (Table S1). The five obtained responses (metal removals) were transformed in polynomial equations in function of the pro- portion of the three components (FE, OA, and RI) (Table S2). These equations can be plotted by contour graphs. The mixture contour plots for each response are shown in Fig. 3. The diagrams illustrate the effect of the biosorbent mixture for each metal. A high proportion of $\mathrm{FE}$ in the mixture is required to obtain high removals of $\mathrm{Cu}(\mathrm{II})$ and $\mathrm{Ni}(\mathrm{II})$. However, the removals of $\mathrm{Mn}$ (II) and $\mathrm{Zn}(\mathrm{II})$ increase when a high proportion of RI is used. According to the plot, the adsorption of $\mathrm{Cr}(\mathrm{VI})$ is enhanced when the OA content is increased.

The obtained responses may be combined into a single objective function to simultaneously optimise the removals of the different metals. Based on the obtained parameters, the theoretical optimised biosorbent mixture (OAM) composition was obtained: $0.500 \mathrm{~g}$ FE, $0.137 \mathrm{~g}$ OA and $0.363 \mathrm{~g}$ RI.

The analysis of variance (ANOVA) results indicated that the models are significant, and the system can be described using these models. The predicted values were in agreement with the experimental data (Table 3), indicating that the SCMD is a reliable method for determining the optimum composition of the new biosorbent.

According to the model obtained, the expected removal percentages using the optimised mixture were $85.58 \%, 38.37 \%$, $39.74 \%, 58.15 \%$ and $74.64 \%$ for $\mathrm{Cu}(\mathrm{II}), \mathrm{Cr}(\mathrm{VI}), \mathrm{Ni}(\mathrm{II}), \mathrm{Zn}(\mathrm{II})$ and $\mathrm{Mn}(\mathrm{II})$, respectively. An experiment was conducted using the optimised biosorbent mixture to validate the model with experimental data. The removal levels achieved for $\mathrm{Cu}(\mathrm{II}), \mathrm{Cr}(\mathrm{VI}), \mathrm{Ni}(\mathrm{II}), \mathrm{Zn}(\mathrm{II})$ and $\mathrm{Mn}(\mathrm{II})$ were $87.10 \%, 40.90 \%, 40.73 \%, 55.61 \%$ and $75.69 \%$, respectively. The good agreement between these experimental data and the predicted values along with their standard deviation of less than $5 \%$ confirms the validity and adequacy of the model.

\subsection{Adsorption kinetics and isotherms of the optimised mixture}

\subsubsection{Adsorption kinetics}

When designing a sorption processing system, it is desirable to know the rate at which the metal uptake will occur. Adsorption kinetics provide valuable insights into the mechanism of the reaction and the reaction pathways. Moreover, the time required to complete the process can be estimated.

Fig. 4 shows that metal adsorption increased with time until pseudo-equilibrium was achieved after $180 \mathrm{~min}$. The adsorption process was slower for $\mathrm{Cr}(\mathrm{VI})$, probably due to its presence as anion in solution. Some authors have suggested a three-step indirect reduction mechanism for $\mathrm{Cr}(\mathrm{VI})$ adsorption in wastes, which would slow the process (Park et al., 2008). That mechanism includes the fixation of anionic chromium to the surface of the biosorbent, the reduction to $\mathrm{Cr}(\mathrm{III})$ and, finally, metal complexation with adjacent groups on the surface of the biosorbent. The results of the experiments in which $\mathrm{Cr}$ (III) was not detected in the liquid suggest that this three-step mechanism may be involved.

Pseudo-first and pseudo-second order kinetics have been frequently used to describe the experimental data. The models were 


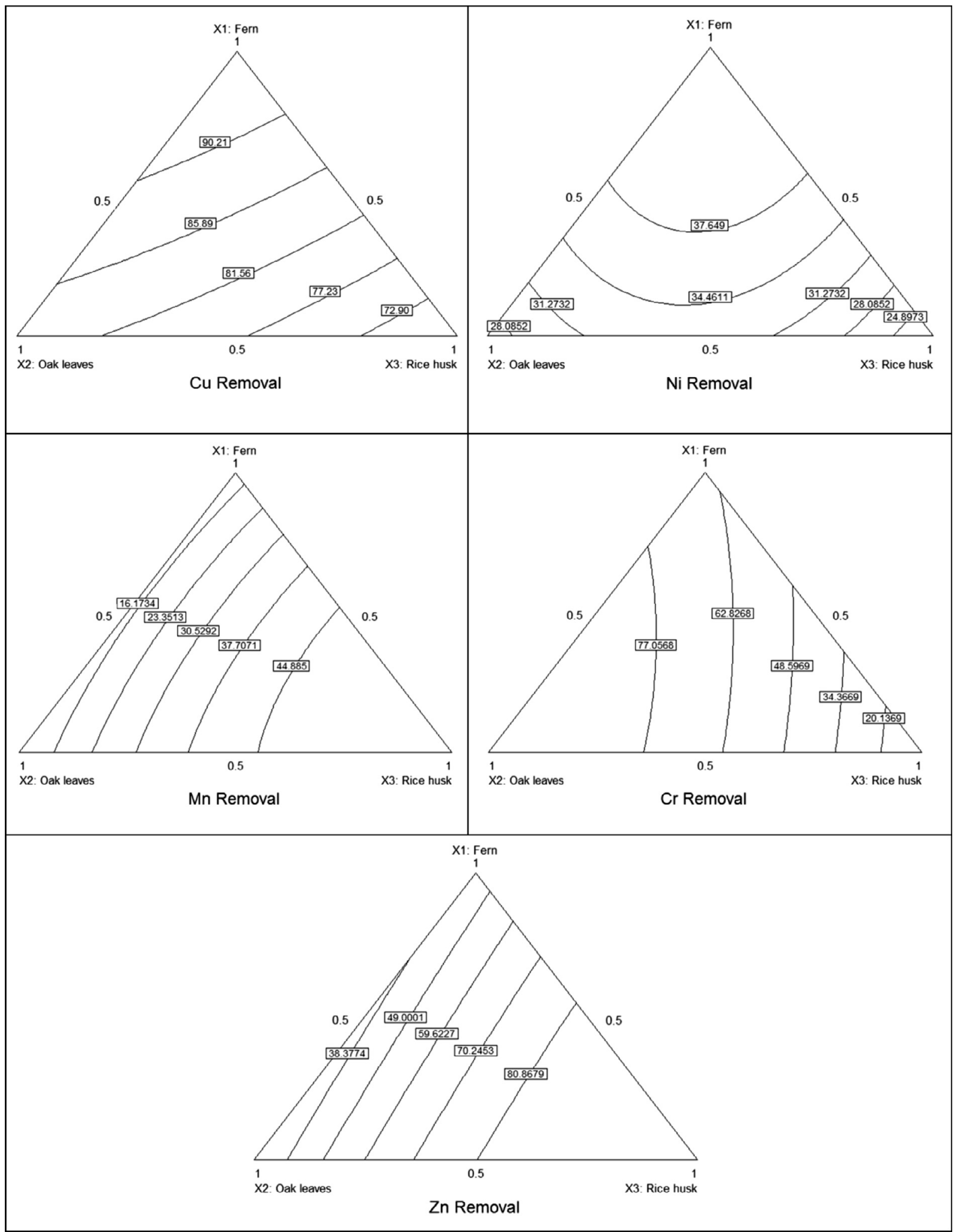

Fig. 3. Triangular-dimensional contour diagrams showing the effect of the different biosorbents on the metal removal.

adjusted to the results, and the data were well fit by a pseudo-first order kinetic equation:

$q_{\mathrm{t}}=q_{\mathrm{e}}\left(1-\exp \left(k_{1} \cdot t\right)\right)$
The kinetic parameters were determined and compared with the experimental values. The calculated values of $q_{\mathrm{e}}$ agree well with those obtained experimentally. The experimental data are compared with the pseudo-first order model for the different metals in Fig. 4. 
Table 3

ANOVA parameters obtained for the SCMD.

\begin{tabular}{|c|c|c|c|c|c|c|c|}
\hline Metal & Model & Std. dev. & $\mathrm{R}^{2}$ & $\begin{array}{l}\text { Adjusted } \\
\mathrm{R}^{2}\end{array}$ & $\begin{array}{l}\text { Predicted } \\
\mathrm{R}^{2}\end{array}$ & $F$ value & $\begin{array}{l}p \text {-Value } \\
\text { Prob }>F\end{array}$ \\
\hline $\mathrm{Cu}$ & Quadratic & 0.7500 & 0.9948 & 0.9916 & 0.9874 & 308.54 & $<0.0001$ \\
\hline $\mathrm{Ni}$ & Quadratic & 1.5801 & 0.9655 & 0.9439 & 0.8909 & 44.71 & $<0.0001$ \\
\hline Mn & Quadratic & 2.3820 & 0.9877 & 0.9800 & 0.9591 & 128.09 & $<0.0001$ \\
\hline $\mathrm{Cr}$ & Quadratic & 1.5851 & 0.9980 & 0.9967 & 0.9950 & 786.46 & $<0.0001$ \\
\hline $\mathrm{Zn}$ & Quadratic & 1.1293 & 0.9986 & 0.9978 & 0.9941 & 1186.83 & $<0.0001$ \\
\hline
\end{tabular}

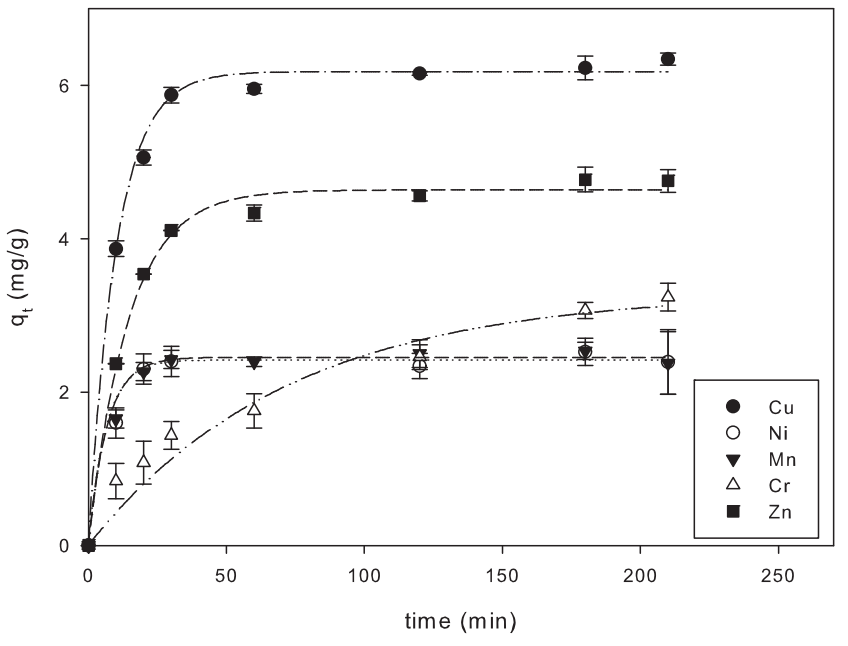

Fig. 4. Pseudo-first order kinetic fitting to the data obtained under the optimised conditions.

The studied kinetic models cannot identify the adsorption mechanism. Usually, the intraparticle diffusion model is used to identify the adsorption mechanism. The effect of intraparticle diffusion resistance on adsorption can be determined fitting the expression to the data:

$q_{\mathrm{t}}=k_{\mathrm{id}} \cdot t^{0.5}+I$

where $k_{\text {id }}$ is the intra-particle diffusion rate constant $\left(\mathrm{mg} /\left(\mathrm{g} \mathrm{min}{ }^{2}\right)\right.$ ). Values of $I$ give information regarding the thickness of boundary layer; i.e., a larger intercept corresponds to a greater boundary layer effect. If the intraparticle diffusion is the only rate-controlling step in the process, the linear plot of $q_{\mathrm{t}}$ against $t^{0.5}$ intersects the origin (Rosales et al., 2012). The obtained results showed that the regression is not linear over the whole time range, but can be divided in a few linear regions (Fig. S4). In each of the metals, two linear segments are evident. Therefore, the adsorption process for the studied system followed two stages. The slopes, $k_{\mathrm{id} 1}$ and $k_{\mathrm{id} 2}$ (Table 4 ), of the linear segments indicated the rates of the adsorption during the two stages. Therefore, surface adsorption and intraparticle diffusion contribute to the metal adsorption (Rosales et al., 2012; Chen et al., 2010).

\subsubsection{Adsorption isotherms}

The elucidation of appropriate adsorption equilibrium correlation curves is required to optimise the design of an adsorption system and compare it with different systems for metal removal from polluted waters. Adsorption isotherm models have been widely used to describe the adsorption process and investigate adsorption mechanisms. The equilibrium state has been described by common two-parameter (Langmuir and Freundlich) and three-parameter (Sips and Redlich-Peterson) adsorption isotherm models (Table 5). The three-parameter models reflect the combined features of the Langmuir and Freundlich models. The equilibrium data were analysed using these two- and three-parameter models. Table 5 shows the parameters of the different isotherm equations evaluated for the optimised mixture of biosorbents along and the corresponding linear regression coefficient $\left(R^{2}\right)$.

After fitting the experimental data by the different models, the Sips and Redlich isotherms were reduced to the Langmuir expression for all the metals except chromium. The results indicate a better fitting of the experimental data by the Langmuir isotherm.

The favourable Langmuir isotherm adsorption can be expressed in terms of a dimensionless constant separation factor or equilibrium parameter $R_{\mathrm{L}}$ (Weber and Chakraborty, 1974):

$R_{\mathrm{L}}=1 /\left(1+b_{\mathrm{L}} \cdot \mathrm{C}_{0}\right)$

where $b_{\mathrm{L}}$ is the Langmuir constant, and $C_{0}$ is the initial metal concentration. The value of $R_{\mathrm{L}}$ indicates whether the isotherm is irreversible $\left(R_{\mathrm{L}}=0\right)$, favourable $\left(0<R_{\mathrm{L}}<1\right)$, linear $\left(R_{\mathrm{L}}=1\right)$ or unfavourable $\left(R_{\mathrm{L}}>1\right)$. The equilibrium parameters were calculated for metal adsorption using OAM, and the adsorption is favourable for all of the studied metals.

The adsorption capacity obtained from Langmuir model increases in the order: $\mathrm{Ni}(\mathrm{II})<\mathrm{Mn}$ (II) $<\mathrm{Zn}$ (II) $<\mathrm{Cr}$ ( $\mathrm{VI})<\mathrm{Cu}$ (II). This can be attributed to adsorption combined with ion exchange mechanism and, ionic attraction of positively charged metal ions, including chromium positively charged after reduction, and negatively charged carboxylic groups (Krishnani et al., 2008).

Table 4

Obtained parameters for pseudo-first order and intraparticle diffusion model kinetics.

\begin{tabular}{|c|c|c|c|c|c|c|}
\hline & Parameters & $\mathrm{Cu}$ & $\mathrm{Ni}$ & Mn & $\mathrm{Cr}$ & $\mathrm{Zn}$ \\
\hline \multirow{3}{*}{ Pseudo-first order model } & $q_{\mathrm{e}}$ & 6.1801 & 2.419 & 2.4536 & 3.3039 & 4.6378 \\
\hline & $k_{1}$ & 0.0979 & 0.1565 & 0.1474 & 0.0139 & 0.0689 \\
\hline & $R^{2}$ & 0.9976 & 0.9962 & 0.9964 & 0.9763 & 0.9946 \\
\hline \multirow[t]{6}{*}{ Intraparticle diffusion model } & $k_{\mathrm{id} 1}$ & 0.8679 & 0.3536 & 0.3418 & 0.2536 & 0.7584 \\
\hline & $I_{1}$ & 1.1416 & 0.5535 & 0.6208 & 0.0103 & 0.0251 \\
\hline & $R^{2}$ & 0.999 & 0.8912 & 0.9366 & 0.9773 & 0.9855 \\
\hline & $k_{\mathrm{id} 2}$ & 0.0507 & 0.0061 & 0.0046 & 0.2239 & 0.0668 \\
\hline & $I_{2}$ & 5.5826 & 2.3461 & 2.4001 & 0.0189 & 3.8266 \\
\hline & $R^{2}$ & 0.9808 & 0.0982 & 0.0636 & 0.9980 & 0.9668 \\
\hline
\end{tabular}


Table 5

Fits of the optimised biosorbent mixture metal adsorption data using different isotherm models.

\begin{tabular}{|c|c|c|c|c|c|c|}
\hline & Parameters & $\mathrm{Cu}$ & $\mathrm{Ni}$ & Mn & $\mathrm{Cr}$ & $\mathrm{Zn}$ \\
\hline Langmuir $q_{e}=q_{\max } \cdot b_{\mathrm{L}} \cdot C_{\mathrm{e}} /\left(1+b_{\mathrm{L}} \cdot C_{\mathrm{e}}\right)$ & $\begin{array}{l}q_{\max } \\
b_{\mathrm{L}} \\
R^{2}\end{array}$ & $\begin{array}{c}32.517 \\
0.046 \\
0.9786\end{array}$ & $\begin{array}{l}3.901 \\
0.194 \\
0.9412\end{array}$ & $\begin{array}{l}4.675 \\
0.081 \\
0.9415\end{array}$ & $\begin{array}{c}23.801 \\
0.079 \\
0.9579\end{array}$ & $\begin{array}{l}6.823 \\
0.599 \\
0.9385\end{array}$ \\
\hline Freundlich $q_{e}=K_{\mathrm{F}} \cdot C_{e}{ }^{1 / n_{\mathrm{F}}}$ & $\begin{array}{l}K_{\mathrm{F}} \\
n_{\mathrm{F}} \\
R^{2}\end{array}$ & $\begin{array}{l}3.365 \\
2.400 \\
0.9065\end{array}$ & $\begin{array}{l}1.569 \\
5.917 \\
0.7103\end{array}$ & $\begin{array}{l}1.209 \\
4.316 \\
0.7483\end{array}$ & $\begin{array}{l}3.341 \\
2.687 \\
0.9258\end{array}$ & $\begin{array}{l}3.154 \\
6.653 \\
0.6950\end{array}$ \\
\hline Sips $q_{e}=K_{\mathrm{S}} \cdot C_{e}^{\beta_{\mathrm{S}}} /\left(1+a_{\mathrm{S}} \cdot C_{e}{ }^{\beta_{\mathrm{S}}}\right)$ & $\begin{array}{l}K_{\mathrm{S}} \\
\beta_{\mathrm{S}} \\
a_{\mathrm{S}} \\
R^{2}\end{array}$ & $\begin{array}{l}1.486 \\
1.000 \\
0.046 \\
0.9786\end{array}$ & $\begin{array}{l}0.756 \\
1.000 \\
0.194 \\
0.9412\end{array}$ & $\begin{array}{l}0.382 \\
1.000 \\
0.087 \\
0.8715\end{array}$ & $\begin{array}{l}2.160 \\
0.8835 \\
0.086 \\
0.9587\end{array}$ & $\begin{array}{l}4.090 \\
1.000 \\
0.599 \\
0.9385\end{array}$ \\
\hline Redlich-Peterson $q_{e}=K_{\mathrm{RP}} \cdot C_{e} /\left(1+a_{\mathrm{RP}} \cdot C_{e}{ }^{\beta_{\mathrm{RP}}}\right)$ & $\begin{array}{l}K_{\mathrm{RP}} \\
\beta_{\mathrm{RP}} \\
a_{\mathrm{RP}} \\
R^{2}\end{array}$ & $\begin{array}{l}1.499 \\
1.000 \\
0.048 \\
0.9786\end{array}$ & $\begin{array}{l}0.756 \\
1.000 \\
0.194 \\
0.9412\end{array}$ & $\begin{array}{l}0.380 \\
1.000 \\
0.081 \\
0.9415\end{array}$ & $\begin{array}{l}2.386 \\
0.877 \\
0.188 \\
0.9660\end{array}$ & $\begin{array}{l}4.090 \\
1.000 \\
0.600 \\
0.9375\end{array}$ \\
\hline
\end{tabular}

\subsection{Mechanism of the adsorption process}

The effective use of the biosorbent mixture requires understanding the chemical nature of the metal binding process. Therefore, the OAM has been chemically pretreated to inactivate different groups and study the behaviour of the system under those conditions.

When the hydroxyl and phenolic groups of the biosorbent mixture were methylated (FO-ME) using formaldehyde, the mixture's removal capacities for $\mathrm{Ni}(\mathrm{II}), \mathrm{Mn}(\mathrm{II})$ and $\mathrm{Zn}$ (II) were significantly reduced. Meanwhile, $\mathrm{Cu}(\mathrm{II})$ and $\mathrm{Cr}(\mathrm{VI})$ removals were not affected. Therefore, we can conclude that the adsorption of $\mathrm{Cu}(\mathrm{II})$ and $\mathrm{Cr}(\mathrm{VI})$ is not influenced by the absence of these hydroxyl and phenolic groups.

On the other hand, if the metal binding occurs through interaction with carboxyl groups, chemical modification that reduces the availability of carboxyl groups for metal complexation should cause a marked reduction in their adsorption. Therefore, the optimised biosorbent mixture was pre-treated with HM-ME. This modification esterifies the carboxyl functional groups. The FTIR results showed that the $-\mathrm{OH}$ functional group in OAM was replaced by $\mathrm{C}=\mathrm{O}$ and $\mathrm{C}-\mathrm{O}$ groups after esterification (Wahi et al., 2013). The esterification significantly reduced the removals of $\mathrm{Cu}(\mathrm{II}), \mathrm{Ni}(\mathrm{II})$, $\mathrm{Mn}(\mathrm{II})$ and $\mathrm{Zn}(\mathrm{II})$, while the removal of $\mathrm{Cr}(\mathrm{VI})$ was significantly increased (Fig. 5). It can be concluded that $\mathrm{Cu}$ (II) binding to biomass is mainly related to the availability of carboxylic groups.

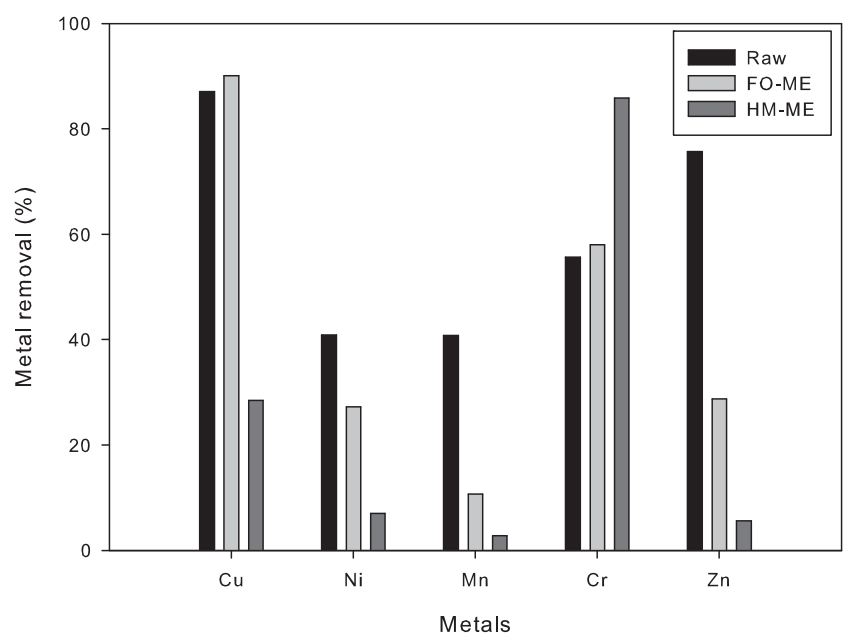

Fig. 5. Comparison between optimised biosorbent mixture untreated, pretreated with formaldehyde FO-ME and pre-treated with HCl-methanol HM-ME.
Table 6

Recovery percentage of the tested metals for the optimised biosorbent mixture.

\begin{tabular}{llcr}
\hline & Water (\%) & $\mathrm{HNO}_{3}(\%)$ & $\mathrm{HCl}(\%)$ \\
\hline $\mathrm{Cu}$ & 1.71 & 100.00 & 100.00 \\
$\mathrm{Ni}$ & 2.09 & 100.00 & 100.00 \\
$\mathrm{Mn}$ & 2.41 & 100.00 & 100.00 \\
$\mathrm{Cr}$ & 0.17 & 10.55 & 5.96 \\
$\mathrm{Zn}$ & 0.70 & 97.98 & 97.81 \\
\hline
\end{tabular}

Moreover, the esterification of OAM also increases the adsorption of anionic metals in solution due to the reduction in the negatively charged groups on biomass surfaces, avoiding charge repulsion.

The other three metals in the synthetic wastewater [ $\mathrm{Ni}(\mathrm{II})$, $\mathrm{Mn}(\mathrm{II})$ and $\mathrm{Zn}(\mathrm{II})]$ did not present any clear adsorption preference after the studied pretreatment modifications.

\subsection{Recovery of metals}

The desorption process used to recover the biosorbent is extremely important to assess the biosorbent's potential for reuse. The metal recovery from solution may be based on different mechanisms (precipitation, complexation or ion exchange) (Lezcano et al., 2011).

Different eluents (water, $\mathrm{HCl}$ and $\mathrm{HNO}_{3}$ ) were tested to evaluate the recovery of metals in OAM (Table 6). When water was used in the process, there was almost no metal desorption. The use of acidic solutions resulted in a fairly good desorption ability; almost total desorption was achieved for $\mathrm{Cu}, \mathrm{Ni}, \mathrm{Mn}$ and $\mathrm{Zn}$. However, $\mathrm{Cr}$ presented almost no desorption, probably due to its presence as an anion as the negative charge is not exchanged with the protons.

The obtained results support the hypothesis of an ion-exchange mechanism being involved in the binding of cations. The results are in accordance with the best fit of the isotherms (Langmuir model), which indicated the dominance of the ion exchange mechanism (Abdolali et al., 2014b). Therefore, $\mathrm{HNO}_{3}$ and $\mathrm{HCl}$ are recommended as desorption agents for the multi-metal mixture.

\section{Conclusions}

The different agroforestry wastes tested appear to have promising potential as biosorbents for metal capture. A significant improvement in removal activity was obtained when a mixture of biosorbents was evaluated and optimised. The selectivity order of $\mathrm{OAM}$ in this multi-metal system is $\mathrm{Cu}>\mathrm{Zn}>\mathrm{Cr}>\mathrm{Ni}>\mathrm{Mn}$, and the isotherm data are well fit by the Langmuir model. The ion-exchange mechanism is involved in the binding of metals to the biosorbent. 
The optimised biosorbent appears to be a promising material for the removal of metals, thus reducing environmental pollution.

\section{Acknowledgements}

This work has been funded by the Spanish Ministry of Economy and Competitiveness, Xunta de Galicia and ERDF Funds (Projects CTM 2011-25389 and GRC 2013/003).The authors are grateful to Xunta de Galicia for financial support of the researcher Emilio Rosales under a postdoctoral Grant and the Spanish Ministry of Economy and Competitiveness for financial support of the researcher Marta Pazos under a Ramón y Cajal Grant.

\section{Appendix A. Supplementary data}

Supplementary data associated with this article can be found, in the online version, at http://dx.doi.org/10.1016/j.biortech.2015.01. 094.

\section{References}

Abdolali, A., Guo, W.S., Ngo, H.H., Chen, S.S., Nguyen, N.C., Tung, K.L., 2014a. Typical lignocellulosic wastes and by-products for biosorption process in water and wastewater treatment: a critical review. Bioresour. Technol. 160, 57-66.

Abdolali, A., Ngo, H.H., Guo, W.S., Lee, D.J., Tung, K.L., Wang, X.C., 2014b. Development and evaluation of a new multi-metal binding biosorbent. Bioresour. Technol. 160, 98-106.

Alothman, ZA, Naushad, M. Ali, R, 2013, Kinetic, equilibrium isotherm and thermodynamic studies of $\mathrm{Cr}(\mathrm{VI})$ adsorption onto low-cost adsorbent developed from peanut shell activated with phosphoric acid. Environ. Sci. Pollut. Res. 20, 3351-3365.

Barriada, J.L., Caridad, S., Lodeiro, P., Herrero, R., Sastre de Vicente, M.E., 2009. Physicochemical characterisation of the ubiquitous bracken fern as useful biomaterial for preconcentration of heavy metals. Bioresour. Technol. 100, 1561-1567.

Boehm, H.P., 1966. Chemical Identification of Surface Groups. Adv. Catal. 16, 179274.

Brauer, S.L., Wetterhahn, K.E., 1991. Chromium(VI) forms a thiolate complex with glutathione. J. Am. Chem. Soc. 113, 3001-3007.

Chen, R., Zhang, Z., Feng, C., Hu, K., Li, M., Li, Y., Shimizu, K., Chen, N., Sugiura, N., 2010. Application of simplex-centroid mixture design in developing and optimizing ceramic adsorbent for $\mathrm{As}(\mathrm{V})$ removal from water solution. Micropor. Mesopor. Mater. 131, 115-121.

Cobas, M., Sanromán, M.A., Pazos, M., 2014. Box-Behnken methodology for Cr(VI) and leather dyes removal by an eco-friendly biosorbent: F. vesiculosus. Bioresour. Technol. 160, 166-174.

Crini, G., 2006. Non-conventional low-cost adsorbents for dye removal: a review. Bioresour. Technol. 97, 1061-1085.

Deshkar, A.M., Bokade, S.S., Dara, S.S., 1990. Modified Hardwickia binata bark for adsorption of mercury(II) from water. Water Res. 24, 1011-1016.

Fontes, M.P.F., Gomes, P.C., 2003. Simultaneous competitive adsorption of heavy metals by the mineral matrix of tropical soils. Appl. Geochem. 18, 795-804.

Gardea-Torresdey, J.L., 1990. Effect of chemical modification of algal carboxyl groups on metal ion binding. Environ. Sci. Technol. 24, 1372-1378.
Gupta, V.K., Carrott, P.J.M., Ribeiro Carrott, M.M.L., Suhas, 2009. Low-cost adsorbents: growing approach to wastewater treatment a review. Crit. Rev. Environ. Sci. Technol. 39, 783-842.

Hossain, M.A., Ngo, H.H., Guo, W.S., Nghiem, L.D., Hai, F.I., Vigneswaran, S., Nguyen, T.V., 2014a. Competitive adsorption of metals on cabbage waste from multimetal solutions. Bioresour. Technol. 160, 79-88.

Hossain, M.A., Ngo, H.H., Guo, W.S., Nguyen, T.V., Vigneswaran, S., 2014b. Performance of cabbage and cauliflower wastes for heavy metals removal, Desalin. Water Treat. 52, 844-860.

Iglesias, O., Fernández de Dios, M.A., Pazos, M., Sanromán, M.A., 2013. Using ironloaded sepiolite obtained by adsorption as a catalyst in the electro-Fenton oxidation of Reactive Black 5. Environ. Sci. Pollut. Res. 20, 5983-5993.

Komy, Z.R., Abdelraheem, W.H., Ismail, N.M., 2013. Biosorption of $\mathrm{Cu}^{2+}$ by Eichhornia crassipes: physicochemical characterization, biosorption modeling and mechanism. J. King Saud Univ. Sci. 25, 47-56.

Krishnani, K.K., Meng, X., Christodoulatos, C., Boddu, V.M., 2008. Biosorption mechanism of nine different heavy metals onto biomatrix from rice husk. J. Hazard. Mater. 153, 1222-1234.

Lezcano, J.M., González, F., Ballester, A., Blázquez, M.L., Muñoz, J.A., García-Balboa, C., 2011. Sorption and desorption of $\mathrm{Cd}, \mathrm{Cu}$ and $\mathrm{Pb}$ using biomass from an eutrophized habitat in monometallic and bimetallic systems. J. Environ. Manage. 92, 2666-2674.

Li, Q., Chai, L., Wang, Q., Yang, Z., Yan, H., Wang, Y., 2010. Fast esterification of spent grain for enhanced heavy metal ions adsorption. Bioresour. Technol. 101, $3796-$ 3799.

Ma, W., Zong, P., Cheng, Z., Wang, B., Sun, Q. 2014. Adsorption and bio-sorption of nickel ions and reuse for 2-chlorophenol catalytic ozonation oxidation degradation from water. J. Hazard. Mater. 266, 19-25.

Nguyen, T.A.H., Ngo, H.H., Guo, W.S., Zhang, J., Liang, S., Yue, Q.Y., Li, Q., Nguyen, T.V., 2013. Applicability of agricultural waste and by-products for adsorptive removal of heavy metals from wastewater. Bioresour. Technol. 148, 574-585.

Noh, J.S., Schwarz, J.A., 2013. Estimation of the point of zero charge of simple oxides by mass titration. J. Colloid Interface Sci. 130, 157-164.

Padilla-Ortega, E., Leyva-Ramos, R., Flores-Cano, J.V., 2013. Binary adsorption of heavy metals from aqueous solution onto natural clays. Chem. Eng. J. 225, 536546.

Park, D., Lim, S.-R., Yun, Y.-S., Park, J.M., 2008. Development of a new Cr(VI)biosorbent from agricultural biowaste. Bioresour. Technol. 99, 8810-8818.

Pérez Marín, A.B., Aguilar, M.I., Meseguer, V.F., Ortuño, J.F., Sáez, J., Lloréns, M., 2009. Biosorption of chromium(III) by orange (Citrus cinensis) waste: batch and continuous studies. Chem. Eng. J. 155, 199-206.

Popescu, C.-M., Popescu, M.-C., Singurel, G., Vasile, C., Argyropoulos, D.S., Willfor, S., 2007. Spectral characterization of eucalyptus wood. Appl. Spectrosc. 61, 11681177.

Prasad, M.N.V., Freitas, H., 2000. Removal of toxic metals from solution by leaf, stem and root phytomass of Quercus ilex L. (holly oak). Environ. Pollut. 110, 277-283.

Rosales, E., Pazos, M., Sanromán, M.A., Tavares, T., 2012. Application of zeoliteArthrobacter viscosus system for the removal of heavy metal and dye: chromium and azure B. Desalination 284, 150-156.

Wahi, R., Chuah, L.A., Choong, T.S.Y., Ngaini, Z., Nourouzi, M.M., 2013. Oil removal from aqueous state by natural fibrous sorbent: an overview. Sep. Purif. Technol. 113, 51-63.

Weber, T.W., Chakraborty, R.K., 1974. Pore and solid diffusion models for fixed bed adsorbents. J. Am. Inst. Chem. Eng. 20, 228-238.

Yao, Z.-Y., Qi, J.-H., Wang, L.-H., 2010. Equilibrium, kinetic and thermodynamic studies on the biosorption of $\mathrm{Cu}(\mathrm{II})$ onto chestnut shell. J. Hazard. Mater. 174, 137-143.

Yoshiara, L.Y., Madeira, T.B., Delaroza, F., Da Silva, J.B., Ida, E.I., 2012. Optimization of soy isoflavone extraction with different solvents using the simplex-centroid mixture design. Int. J. Food Sci. Nutr. 63, 978-986. 